\title{
Recreational Activities for Senior Citizens
}

\author{
*Bhawana Singh, ${ }^{* *}$ U. V. Kiran \\ *Research Scholar **Assistant Professor \\ Department of Human Development \& Family Studies, School for Home Sciences, \\ Babasaheb Bhimrao Ambedkar Central University Lucknow, India- 225026
}

\begin{abstract}
Recreation plays a key role in the well-being of older adults and in enhancing their quality of life. For seniors, as for people of all ages, involvement in recreation activities can satisfy a variety of needs. Among the important benefits of recreation for the senior population is increased health and fitness, as well as opportunities for socializing, for using skills and talents developed throughout their lifetime, and for learning new skills. The aim of this article is to dwell upon various recreational activities for the elderly. These activities are very useful to them as they can spend their leisure time and enjoy by doing interesting tasks. The senior population is quite varied, with a diversity of interests, strengths, and abilities. Some seniors have enjoyed a positive use of leisure throughout their life, and are able to find appropriate activities to suit their changing physical abilities and interests. Other seniors, however, may not be aware of the potential positive values of recreation.
\end{abstract}

Keywords: Elderly, physical activity, recreational activity,

\section{Introduction}

The ageing of population is an obvious consequence of the process of demographic transition. While the countries of the West have already experienced and have planned for their elderly population, it is only in the last one and half decades that countries in Asia too are facing a steady growth of the elderly, as a result of the decline in fertility and mortality, better medical and health care and improvements in the overall quality of life of people. Within Asia, as India and China are the two largest countries in the region, it is expected that they would have a significant proportion of the World's elderly because of their large population base. In fact, the situation in India presents two different scenarios with certain states grappling with curbing their high fertility rates while others, which have controlled high fertility rates, are already experiencing or are poised to experience an increase in their elderly population.

There has been a progressive increase in both the number and proportion of the aged in India over time, particularly after 1951. Between 1901 and 1951, the proportion of population over age 60 increased marginally from 5 percent to 5.4 percent, while by 2001 this had increased to 7.0 percent. When changes in the decadal growth rate in the general population are compared with those for the elderly population, it is noted that the latter grew at a relatively much faster rate than the general population, since 1951. Furthermore, the decadal percent increase in the elderly population for the period 2001-2011 is likely to be more than double the rate of increase of the general population. The size of the elderly rose in absolute terms during the last century from 12 million in 1901 to approximately 71 million in 2001 and is likely to reach 113 million in 2016. Yet another feature of ageing in India is the fact that the proportion of elderly is much higher in the rural areas than in the urban areas.

In recent years, there has been an increase of aging in the society. The aging of the population can lead to an increase in the number of individuals at risk for chronic diseases. In an article from the Center for Disease Control and Prevention's Healthy Aging Network, physical activity (PA) was considered one key element for determining health status. In fact, evidence suggests that PA is associated with more years of life, self-perceived healthy life, years without impairment in daily life activities, lower rates of functional decline, lower risk of mortality, increased longevity, reduced risk of type 2 diabetes, and better quality of life.

Being active throughout the majority of one's lifetime has an important influence on overall health and well-being. The widely known definition of physical activity (PA) as "any bodily movement produced by the contraction of skeletal muscle that increases energy expenditure above a basal level". PA has been found to check many long lasting health problems as well as to promote mental health and well-being. Lower mortality rates occur among those who become physically active late in life as compared to those who were active in early life and stopped exercising.

Outdoor recreational PA, defined as "to be outside in natural or cultural landscapes for well-being and encounters with nature without demands for competition" has been shown to be particularly good for promoting 
well-being. PA performed outdoors in original settings has been found to have restorative effects on people's health and reduce mental fatigue.

\section{Relationship between Mental Health and Organized Recreational Activity}

A review of current literature indicates that people who participate in sports clubs and organized recreational activity enjoy better mental health, are more alert, and more pliable against the stresses of modern living. Engaged in recreational groups and socially supported physical activity is shown to overcome stress, anxiety and depression, and mitigate the symptoms of Alzheimer's disease. Violent crime also reduces significantly when participation in community activities increases.

\section{Links between mental health and group activities}

Participation in sports and recreation activities can decrease stress, depression and anxiety. Engaged in the group recreation provides a sense of attachment, belongingness and positive values. According to Bandura's social cognitive theory, behaviour is shaped by the interaction between individual and environmental factors. This theory emphasizes the influence of social interaction in relation to behaviour. There are both direct and indirect links between participation in group activity and mental health.

\section{Recreation activities for seniors}

Gone are the days when retirees used to sit at home and feel old. It is important for older adults to stay active after retirement and be participative in the community. The choices for outdoor recreation are unavoidable. There are many centers that offer various classes and courses in exercise programs, crafts and arts, and other outings.

PA is a wide-ranging term that includes a variety of activities. Recreation activities for seniors provide long term advantages. Higher fitness levels, improved health and social interactions are few of the benefits of indulging in fun activities. It is therapeutic refreshment for both the mind and body.

\section{Walking}

Walking is one of the most common exercises. It is enjoyable and a social activity that can also be carried on with friends and family members. There is nothing like avail some fresh air in lush green surroundings. It helps to reduce depression and lower down the stress, thus maintaining emotional well being whether you have a company or not. It is perhaps the best form of physical exercise for all age groups. The chance to inhale fresh air and see the greenery helps in reducing depression and helps maintain emotional well being. It also gives a chance to meet other people. The older adults must wear comfortable walking shoes, which will give support to their feet and they will not make them feel tired. For those who feel the requirement for intermediate support or a need to hold on to something, carrying a stick is a good idea. For those who can go for longer walks easily, or choose to go and sit in the park, or garden, carrying a bottle of water would help them to take care of thirst. However, if one is on a wheelchair, going to parks and gardens may not be very feasible owing to the physical barriers. There is however another boon - the malls, which can be accessed even in wheelchairs, with a helper. For the wheelchair borne, these walks may not be possible everyday but can be clubbed with window shopping, if one is interested and perhaps a coffee, with a friend, acquaintance, or a family member.

\section{Bird Watching}

A great activity for people who love nature but cannot go for nature walks, in the fields or forests because of physical problems or deformities, lack of transport, companions or any other practical problem, then there is no need to go to the forests for this. A park is the good idea to start this activity.

\section{Photography}

Another activity is photography. For which a camera is to be needed. A practical way is getting hold of a digital camera, and clicking whatever interesting, and capturing it in the camera. It could be a theme - like nature, or vehicles, or humans, anything that holds attention. This can then be even consolidated into a scrapbook kind of file in a computer.

\section{Gardening}

Gardening is a nice leisure activity for older adults. It helps people to connect with the nature. Just need a small patch of land or a plot that will keep the elderly occupied, or a few pots that can keep in the balcony or just outside the house, and some bright coloured equipment. One can grow vegetables and create a beautiful garden. This activity should be followed only during the morning and evening hours avoiding peak hours. A purposeful activity that connects to the nature. A few websites and books are enough to help the elderly, create a 
garden and may be even grow some vegetables. It is advised, not to step out for doing gardening when it is very warm outside, do it in the mornings and evenings. It is also obvious that, do not lift out anything heavy like pots, which might cause strain to the back. If already have a back problem then it would help to put the pots in an elevated place so that the elderly people do not have to bend too much.

\section{Sports}

If physical health and doctor permits, sports is a very good physical exercise and recreational activity be it swimming, badminton, tennis, golf or any other which may interesting to the older adults. It is also an excellent way to meet other people socially.

\section{Exercise}

This is one activity suggested by all doctors and health practitioners for all age groups, the senior citizens are not different. Different forms of exercise are now being practiced which are a great form of relaxation apart from helping physical and mental fitness.

Yoga

Yoga is aimed at achieving the union with supreme consciousness. However, it helps to achieve physical as well as mental fitness. A TV series by a professional Yoga Guru gives an idea about the benefits of Yoga and how to practice. It is however essential to learn appropriate and right postures from a good teacher of Yoga.

\section{Tai-Chi}

Chinese martial art that is getting a lot of recognition, especially for older adults because of its 'soft skills' and health and longevity benefits. It has long movements, which flow in a slow and graceful manner. Each posture flows into the next without any pause. Just as Yoga, Tai-chi is very beneficial for various diseases like osteoporosis, diabetes, arthritis etc.

\section{Art of living}

The Art of Living initiatives strive to uphold the dignity of every human being on the earth, offering each individual a stress-free life, a healthy body and the opportunity to maximize their potential for personal and spiritual growth. Sri Ravi Shankar has designed many self-development techniques which can easily be integrated into daily life to calm the mind and in still confidence and enthusiasm.

\section{Mental Exercise}

Senior citizens should be encouraged to take part in mind games. They should solve puzzles like crosswords, brain teasers and sudoku focus on doing mathematical calculations. These are very brneficial for exercising the mind. It also prevents from the serious old age ailments like Alzheimer's disease.

The list of outdoor activities is not limited to this. Older adults can use their own imagination and do whatever they enjoy, to occupy their time and give them a sense of fulfilment. They perhaps would be benefited more if they set aside a time for the activity/activities that they want to do, for example, go for a walk. If they set a time everyday as their 'walk time', they would be mentally prepared and physically groomed, their brain would be disciplined and they would look forward to it.

\section{Indoor Activities}

Though outdoor activities should be preferred but when conditions are not in older adult's favour then there are several activities like listening to music, scrap-booking and collage making. It is fun and creative to gather all the photographs and momentos together. Spending time with family members or friends and playing board games with other elderly friends is also a stress buster.

- Seniors should be involved in other activities like sewing, dancing, bird watching, art classes, card playing, parties etc. There are many centres that are free where elders can volunteer and explore their creativity. Dancing to your favourite beats is rejuvenating and stress buster.

- Field trips and visiting the outskirts of the city or going for a picnic are enjoyable and fun. Many organizations also have cultural activities and competition.

Elderly can enjoy the club culture in the retirement community and indulge in activities like cards, swimming pool, health clubs and sports like table tennis, billiards, lawn tennis, snooker and even visit the library.

It is the best time to explore creative side for senior citizens. If older adults have an inclination towards a particular activity or hobby like photography or dancing then they should be given a boost and motivation to nurture their talent. Keep them engaged in various activities for emotional, physical and spiritual well being. 
Elderly men and women often need recreational activities to stay better in mental and physical health. There are various recreational activities available to elderly women and men to suit almost any interest. Before starting any physical recreation, elderly women and men should consult a doctor to determine how much activity is appropriate.

\section{Volunteer Recreations}

Older persons who are in good physical and mental health can volunteer at any organizations hospitals or animal shelters. These types of volunteer activities not only make a difference in the other's lives, but give an elderly people a sense of purpose.

\section{Old Favourites}

Elderly can work on their favourite recreations to stay active and healthy. Old favourites might include interests such as fishing or gardening or it might include games like cards, bingo or puzzles, crossword. Singing, cooking and Reading might even fall in the category of old favourites. For elderly women and men who have physical challenges preventing the old favourites, bringing it into their space can help as well.

\section{Community Centre Recreations}

Community centres offer recreational activities for all age group, including the elderly. Recreations for senior citizens might include swimming recreations or sports geared to healthy older adults. Usually, community centre recreations are sports and fitness, but games like cards, bingo as well as chess might be available.

\section{Outdoor Recreation}

The child of an elderly parent might take his parent out for a day for fishing, an outdoor sport such as hunting, hiking or even golf, depending on the outdoor activities. Every healthy elderly person is able to enjoy outdoor recreations with children. For those who are physical disabled, recreations like fishing are ideal, as it allows them to enjoy the outdoors while sitting still.

\section{Recreational Activities for the Older Adults}

Old age is often referred to as the 'second childhood'. During this stage most of the elderly people tend to behave like a small child, not listening to what others say and become stubborn. This might be due to the reason that majority of the people incur the problem of brain shrinkage, as they grow older. Therefore, we need to give the senior citizens special care and attention and treat them just like our little ones. Keeping them busy in recreational activities is the best idea, to fill the gap that comes along with retirement and old age.

\section{Recreational Activity Ideas for Older Adults}

- Enroll the elderly person in a club that organizes activities involving the active participation of volunteers. If the club organizes health camps and rehab, competitions or hobby classes, it will be the best option for the older adults, who wants to pass their leisure time in a productive way.

- A fun way to keep a senior citizen busy for the maximum time is to arrange arts and crafts competitions. If elderly's residential association organizes cultural activities and day trips, be sure that the elderly person must take part in them. It will definitely rejuvenate their spirit.

- Dedicated volunteering in schools, colleges and local community centres can help the senior citizens attain self-satisfaction that they have rendered service during the post-retirement period, without sitting idle.

- To kill the boredom, arrange easy and fun games for the elderly person, when we are spending time with the elderly. This could be as simple as the good old 'passing the parcel' game. Ask the little ones in our family, to play with their grandpa/grandma for some time.

- If an elderly person has inclination towards any type of activity, be sure to address it. For instance, if an elderly is interested in taking photographs, provide them a camera. Take them to the places where they can click nice pictures.

- Reading is something that the majority of older adults like to do, in a free time. Gift some books for them. We may present a library membership to them as well, so that they get the supply of their favourite books all through the year.

- Give food to their brain - organize mental exercises, like puzzles, for the senior citizens. We can also get some printed brain teasers, like crossword puzzles and Sudoku.

\section{Physical activity for older adults}

Regular exercise is a best way to live a long and healthy life.

There are many health and lifestyle benefits of physical activity for senior citizens. People, whose lifestyle is active, feel healthy and have an improved sense of wellbeing. Besides feeling better, a regular exercise reduces the risk of diabetes, heart disease, colon cancer and stroke. 


\section{Elderly should be active}

Researches shows that elderly's with active lifestyles are often as healthy as less active people aged 15 years younger.

One of the best ways of living a long and healthy life is through physical exercise. However, physical exercise comes in many ways and forms, including walking, housework and gardening to the shops to buy the milk or newspaper.

Regular physical activity helps reduce the effects of aging such as muscle strength, balance, limited mobility and flexibility. It also reduces the risk of osteoporosis and heart problems, as well as keeping older adults in a happy and healthy frame of mind.

One way older adults are beating the stereotyped "old" image is through remaining socially and physically active. From dancing, golf, bushwalking, swimming, tennis or simply gardening or walking the dog, all these activities play a important role in ensuring their look and feel younger, healthier, and have a better quality of life.

\section{It's never too late to start exercising}

Forget thinking that we (elderly) are too old to do physical exercise - once they become more active they will find that they have more energy, sleep better, and will feel more self confident.

There are no rules or age limits to physical exercise. Irrespective of how old they are or how often they have exercised in the past, there is no time like the present to begin doing regular physical exercise. They will begin to feel healthier and have more energy almost immediately.

The secret is to start off slowly with activities they enjoy, and gradually build on these. It would not seem like a chore if you choose activities they like.

The important thing about taking regular exercise is to start today. Just 30 minutes every day can keep you feeling younger, healthier and more energetic. You can break that 30 minutes down into 10 minute blocks, making the daily amount of physical activity recommended much easier to achieve.

\section{Get started}

Focus on getting started, maintaining a routine and enjoying the benefits of physical activity.

Getting started can be as simple as taking the stairs instead of the escalator, walking to the shops, or getting off the bus one stop earlier. Once they have started these simple things, it is then time to build on this exercise with some other pleasurable physical activities.

Choose activities that they enjoy - you will be surprised at how quickly time goes by. If elderly people enjoy gardening, then make a point of doing it for a little longer. Or take the dog for a longer walk.

Try a few different activities until they find one that suits them. You will find it is then easier to maintain a routine, and they could also make new friends.

It is also important to exercise at times that suit them; otherwise it will feel like a chore. The aim should be to fit physical activity into their everyday schedule.

As people grow older their participation in leisure and recreation activities changes because of life cycle transitions such as retirement from paid work and the "empty nest" experienced by parents as children grow up and leave home. In later years such participation can also be expected to change further because of declining physical and mental capacity. Leisure time has been defined "as a time when people can do what they want to do, away from work and other commitments" (Ministry of Social Development, 2008: 86). Recreation can often involve a physical activity or sport. Leisure and recreation as the Ministry of Social Development describe them in their Social Reports are a means to:

- $\quad$ provide people with a sense of identity and personal autonomy

- $\quad$ add meaning to individual and community life, and

- $\quad$ encourage personal growth and self-expression

The elder people have sufficient time to do what they want to do and can access an adequate range of opportunities for leisure and recreation". The Ministry of Social Development stated that the higher the measure of participation in either physical or cultural and arts activities, the greater the level of wellbeing.

Over the past few decades the relationship between leisure activities and wellbeing in later life has been studied extensively (Havighurst, 1961). Early gerontology researchers maintained activity was positively related to the wellbeing of older people (Havighurst, Neugarten \& Tobin, 1964), and one of the founding theories of ageing was built on this idea. Entitled "activity theory", successful ageing was seen as benefiting from continued or enhanced physical and mental activity in older years. The theory was developed as an opposing view to the "disengagement theory" previously developed by Cumming and Henry (1961), and which suggested that growing older was associated with varying stages of disengagement from society, both in the interests of the individual and of society in general. 
The impact of the cultural and social context on the level of participation of older people in leisure and recreation is an increasing theme in the research. The leisure and recreation pursuits undertaken in one's earlier years are more likely to be continued in one's older years - "older people tend to continue participating in activities with which they are familiar for security as well as reassurance" (Nimrod \& Kleiber, 2007). Leisure and recreational pursuits have often been taken to include activities which are largely physical.

The evidence is compelling. Recreation, physical activity, sports and leisure are not only essential resources for promoting optimal mental health and well-being, but they are critical components of efforts to recover from and stay well when living with a mental illness or addiction.

- Free time context: Term used primarily in the leisure sciences literature to refer to unobligated time, outside of work, school, or self-care activities. Typically we think of this as "free time", such as after school or work, in the evenings and weekends.

- Discretionary time: Term used in the developmental psychology literature to refer to free time. Like the term "free time," this includes the afterschool context as well as evenings and weekends. The term "extracurricular activities" is often used in conjunction with studies of adolescents' discretionary time.

- Leisure: Refers to enjoyable and personally meaningful activity in the free time context. Leisure is often associated with a sense of freedom and intrinsic motivation (doing something because they want to, not because they have to). Categories of leisure typically include: social (e.g., spending time with friends), creative or expressive (e.g., artistic pursuits), cognitive (e.g., reading), spiritual (e.g., meditation) or physical (e.g., walking, gardening).

- Structured Leisure Activities: Refers to leisure or recreation activities that occur in the free time context that are typically deeply engaging (e.g., require an investment of attention and effort) and support personal expression. Examples include volunteering, sports or club activities. This is sometimes also referred to as "active leisure."

- Unstructured Leisure Activities: Unstructured leisure typically refers to "doing nothing" or passive forms of activity that require low levels of engagement and often occur outside of organized recreation or leisure contexts (e.g., going to the movies, hanging out, going to the mall, watching television, listening to music in room). This term is most often used in relation to adolescent or adult leisure.

- Physical Activity: Is often associated with various forms of exercise, but can include vigorous leisure or recreation activities. Examples include: bicycling, gardening, walking, golf, swimming, tennis, etc.

- Recreation: Typically associated with structured or organized group activities which are intentionally designed to benefit communities, groups or individuals. Camaraderie, skill development, fitness and enjoyment tend to be primary motivations for recreation participation. Depending on the degree of specialization, participation with sports, creative arts, or service groups are considered forms of structured recreation participation.

- Sport: Typically defined as an organized, competitive activity, requiring adherence to rules and/or customs and specific skills to play; the objective is often associated with winning or losing. We typically think of sports as being athletic competitions, but competitive games requiring intellectual skills and challenges (e.g., chess) are also considered "sport."

- Play: Although there are many different definitions and theories of play — and adults also play — here we view play as spontaneous, unstructured, child-directed activity which is fun, freely chosen, actively engaging, and intrinsically motivated (e.g., done for its own sake as opposed to having to or for some external reward or achievement motive); it typically involves children interacting with others and/or their environment and may involve the suspension of reality and/or "rules" of play.

\section{References}

[1]. Australian Bureau of Statistics (2006). Sport and Recreation: A Statistical Overview. In. Canberra: Australian Bureau of Statistics.

[2]. Bandura, A. (1997). Social Learning Theory. Englewood Cliffs, NJ: Prentice Hall.

[3]. Berkman, L.F., Glass, T., Brissette, I., Seeman, T. (2000). From social integration to health: Durkheim in the new millenium. Social Science \& Medicine. 51(6):843-857.

[4]. Bhargava, A. (2003). A longitudinal analysis of the risk factors for diabetes and coronary heart disease in the Framingham Offspring Study. Population Health Metrics. 1:3.

[5]. Singh, B. \& Kiran, U.V. (2013). Loneliness among elderly women. International Journal of Humanities and Social Science Invention. 2(1). 1-6

[6]. Boyle, P.A., Buchman, A.S., Wilson, R.S., Bienias, J.L., Bennett, D.A. (2007). Physical activity is associated with incident disability in community-based older persons. J Am Geriatr Soc. 55:195-201.

[7]. Byberg, L., Melhus, H., Gedeborg, R., Sundstrom, J., Ahlbom, A., Zethelius, B., Berglund, L.G., Wolk, A., Michaelsson, K. (2009). Total mortality after changes in leisure time physical activity in 50 year old men: 35 year follow-up of population based cohort. BMJ, 338:b688

[8]. Carcach, C., \& Huntley, C. (2002) Community Participation and Regional Crime. Canberra. Australian Institute of Criminology.

[9]. Christensen, K., Doblhammer, G., Rau, R., \& Vaupel, J.W. (2009) Ageing populations: the challenges ahead. Lancet. 374:11961208 .

[10]. Cumming, E., \& Henry, W. E. (1961). Growing old, the process of disengagement. Basic Books; New York. 
[11]. Demakakos, P., Hamer, M., Stamatakis, E., \& Steptoe, A. (2010). Low-intensity physical activity is associated with reduced risk of incident type 2 diabetes in older adults: evidence from the English Longitudinal Study of Ageing. Diabetologia . 53:1877-85.

[12]. Elsawy, B., \& Higgins, K.E. (2010). Physical activity guidelines for older adults. Am Fam Physician. 81:55 9.

[13]. Fredman, P., Sandell, K., Boman, M., Emmelin, L., Lundmark, L., and Romlid, U. (2006). Outdoor recreation in change Landscapes, experiences, planning and development. Program plan. 08-18.

[14]. Frumkin, H. (2001). Beyond toxicity human health and the natural environment. American Journal of Preventive Medicin. 20:234240.

[15]. Gregg, E.W., Cauley, J.A., Stone, K., Thompson, T.J., Bauer, D.C., Cummings, S.R., Ensrud, K.E. (2003) Study of Osteoporotic Fractures Research Group: Relationship of changes in physical activity and mortality among older women. J Am Med Dir Assoc. 289:2379-86.

[16]. Havighurst, R. (1961). The nature and values of meaningful free-time activity, in R. Kleemeier, (Ed.), Aging and Leisure (pp. 30944). Oxford University Press, New York.

[17]. Havighurst, R. J., Neugarten, B. L., \& Torbin, S. S. (1964). Disengagement and patterns of aging. The Gerontologist, 4, 24.

[18]. Hirsch, C.H., Diehr, P., Newman, A.B., Gerrior, S.A., Pratt, C., Lebowitz, M.D., Jackson, S.A. (2010). Physical Activity and Years of Healthy Life in Older Adults: Results from the Cardiovascular Health study. J Aging Phys Activity. 18:313-334.

[19]. Kaplan, R., Kaplan, S. (1989). The experience of nature: A psychological perspective. Cambridge University Press.

[20]. Keim, N.L., Blanton, C.B., Kretsch, M.J. (2004) America's Obesity Epidemic: Measuring physical activity to promote an active lifestyle. Journal of the American Dietetic Association 104:1398-1409.

[21]. Motl, R.W., McAuley, E. (2010). Physical activity, disability, and quality of life in older adults. Phys Med Rehabil Clin N Am. 21:299-308.

[22]. Nimrod, G., and Kleiber, D. (2007). Reconsidering change and continuity in later life: Toward an innovation theory of successful aging, International Journal of Aging and Human Development, 65, 1-22.

[23]. Paffenberg, R.S., Hyde, R.T., Wing, A.L., Hsieh, C.C. (1986). Physical activity, all-cause mortality and longevity of college alumni. New England Journal of Medicine. 314:605-613.

[24]. Physical Activity Guidelines Advisory Committee: Physical Activity Guidelines Advisory Committee Report, 2008. Washington DC: Department of Health and Human Services; 2008.

[25]. Prohaska, T., Belansky, E., Belza, B., Buchner, D., Marshall, V., McTigue, K., Santariano, W., Wilcox, S. (2006). Physical activity, public health, and aging: Critical issues and research priorities. J Gerontol B Psychol Sci Soc Sci. 6: S352-S356.

[26]. Singh, Bhawana \& Kiran, U. V. (2013). Loneliness among Elderly Women. International Journal of Humanities and Social Sciences. 2(2):10-14.

[27]. Stessman, J., Hammerman-Rozenberg, R., Cohen, A., Ein-Mor, E., Jacobs, J.M. (2009). Physical activity, function, and longevity among the very old. Arch Intern Med. 169:1476-83.

[28]. Suzan, van der Pas and Peggy, Koopman-Boyden Leisure and Recreation Activities, and Wellbeing among Older New Zealanders.

[29]. Ueshima, K., Ishikawa-Takata, K., Yorifuji, T., Suzuki, E., Kashima, S., Takao, S., Sugiyama, M., Ohta, T., Doi, H. (2010). Physical activity and mortality risk in the Japanese elderly: a cohort study. Am J Prev Med. 38:410-8.

[30]. United Nations (2002) Population Division: World Population Ageing 1950-2050. New York: United Nations.

[31]. US Department of Health and Human Services 1996. The Surgeon General's report on physical activity and health. Washington DC: US Government Printing Office;

[32]. VicHealth. Mental Health Promotion Plan 1999-2002. Carlton, Victoria: Victorian Health Promotion Foundation; 1999.

[33]. www.friluftsforskning.se/download/18.6983d52510f51a3d56e80002728/Programplan_Friluftsliv+i+f\%C3\%B6r\%C3\%A4ndring_0 60818.pdf]. Retrieved October 5, 2009 